\title{
Corrosion Inhibition effect of Antimony Potassium Tartrate for Q235 Carbon Steel in NaCl Solutions
}

\author{
Shifang WANG, Yu ZUO, Yuming TANG, Xuhui ZHAO* \\ Beijing Key Laboratory of Electrochemical Process and Technology for Materials, Beijing University \\ of Chemical Technology, Beijing 100029, China \\ *E-mail: xhzhao@mail.buct.edu.cn
}

doi: $10.20964 / 2018.01 .62$

Received: 15 September 2017 / Accepted: 30 October 2017 / Published: 16 December 2017

\begin{abstract}
The inhibition effect of antimony potassium tartrate on the corrosion of Q235 Carbon Steel in $\mathrm{NaCl}$ solutions was studied through weight loss measurement, potentiodynamic polarization, scanning electron microscopy (SEM), and X-ray photoelectron spectroscopy (XPS). Thermodynamic calculations were carried out to explore the adsorption mechanism of antimony potassium tartrate. The results showed that antimony potassium tartrate can inhibit the corrosion of Q235carbon steel in a $0.01 \mathrm{M} \mathrm{NaCl}$ solution. A maximum inhibition efficiency of $63.5 \%$ was observed in the presence of 400 ppm of antimony potassium tartrate. In a $0.01 \mathrm{M} \mathrm{NaCl}+0.15 \mathrm{M} \mathrm{NaHCO}_{3}$ solution, the inhibition efficiency increased drastically and reached $95.6 \%$ in the presence of $300 \mathrm{ppm}$ of antimony potassium tartrate. Both chemical and physical adsorption occurred, and the Langmuir isotherm model was found to accurately describe the process.
\end{abstract}

Keywords: Corrosion inhibition, Antimony potassium tartrate, Carbon steel, Adsorption

\section{$\underline{\text { FULL TEXT }}$}

(C) 2018 The Authors. Published by ESG (www.electrochemsci.org). This article is an open access article distributed under the terms and conditions of the Creative Commons Attribution license (http://creativecommons.org/licenses/by/4.0/). 